\title{
Arbuscular Mycorrhizal Fungi Assisted Cadmium Removal by Water Hyacinth (Eichhornia crassipes (Mart.) Solms) in Polluted Soil and Water
}

\author{
Gunathilaka D.N.M. ${ }^{1}$, Yapa P.N. ${ }^{1 *}$, Hettiarachchi R.P. ${ }^{2}$ \\ ${ }^{1}$ Department of Biological Sciences, Faculty of Applied Sciences, Rajarata University, Sri Lanka \\ ${ }^{2}$ Soils \& Plant Nutrition Department, Rubber Research Institute of Sri Lanka, Sri Lanka \\ *pnyapa40@yahoo.co.uk
}

\begin{abstract}
Heavy metal pollution of soil and water is a major environmental problem, and most conventional remediation approaches do not provide acceptable solutions. Wetland plants are being used successfully for the phytoremediation of trace elements in natural and constructed wetlands. The present study was aimed at assessing the potential of Cadmium $(\mathrm{Cd})$ removal from contaminated soil and water by Eichhornia crassipes (Mart) Solms with the inoculated arbuscular mycorrhizal fungi (AMF). A pot experiment was carried out in the planthouse at the Faculty of Applied Sciences, Rajarata University of Sri Lanka, Mihintale. The water hyacinth plants of similar heights and with number of leaves were taken from the Mihintale tank as the test plants. Pots were filled with the wetland soil, tank water and water hyacinth was introduced with the inoculated AMF and non-inoculated AMF. Different cadmium concentrations were applied to water as $0,5,10,20$ and $50 \mathrm{ppm}$ in different treatments. Water samples were collected at several time intervals $\left(1^{\text {st }}, 3^{\text {rd }}, 7^{\text {th }}, 14^{\text {th }}\right.$ and $52^{\text {nd }}$ days $)$ and on the $52^{\text {nd }}$ day, soil, roots and shoots of the E.crassipes were collected for the analysis of Cd using an Atomic Absorption Spectrophotometry. The percentage AMF colonization, relative growth rate, dry biomass of shoots and roots of E. crassipes were also estimated. The significantly different high $(\mathrm{p}<0.05)$ percentage AMF colonisation, shoot and root $\mathrm{Cd}$ concentration, relative growth rate, dry biomass of roots and shoots were observed in AMF inoculated water hyacinth than non-inoculated, in all levels of cadmium additions. The uptake of $\mathrm{Cd}$ was increased with the increased $\mathrm{Cd}$ additions with the increasing time in all tested $\mathrm{Cd}$ concentrations. Always cadmium accumulation was higher in E. crassipes roots than in shoots. It can be concluded that E. crassipes efficiently hyper-accumulated $\mathrm{Cd}$ in its biomass and tolerated higher concentrations of Cd when inoculated with AMF. Therefore, AMF can be used as root inoculants of Eichhornia to phytoremediate cadmium contaminated soil and water through making it an effective phytoremediating aquatic plant.
\end{abstract}

Keywords: Phytoremediation, Arbuscular Mycorrhizal Fungi (AMF), Water hyacinth, Cadmium, Colonization 